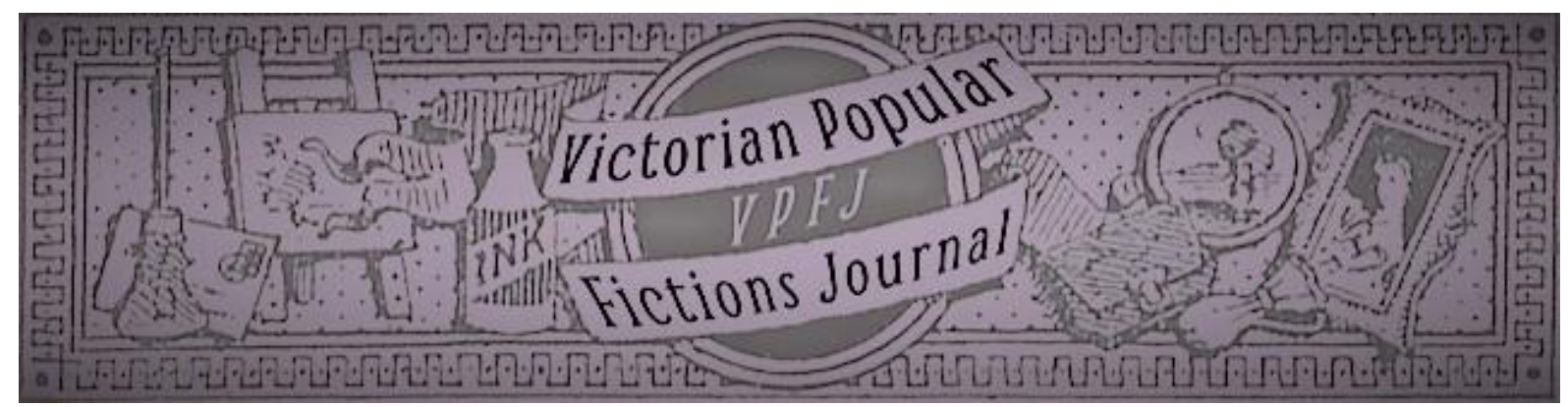

\title{
Picture Stories, 1840-1860, or Problems with Photographs
}

\author{
Jonathan Potter
}

\begin{abstract}
"Picture" stories, a whole genre of short fiction denoted by the central role of a picture, were common in the middle decades of the nineteenth century, from the 1840s to the $1860 \mathrm{~s}$. They featured in periodicals publishing fiction aimed towards middle- and lower-class readers, such as Ainsworth's Magazine, Chamber's Edinburgh Journal, Bentley's Miscellany, and Sharpe's London Magazine of Entertainment and Instruction for General Reading. Titles usually made the genre obvious: e.g. "The Story of a Picture" (1842), "The Fatal Picture" (Elder 1843), "The Adventures of a Picture" (Medwin 1843), "The Unfinished Picture: A Reverie" (Kenney 1845), "The Lost Picture" (1853), "The Unowned Picture" (1856), and "Memoirs of an Old Picture" (1859). Many of the "pictures" in these stories of the 1840s, 1850s, and 1860s are paintings, but not all. Picture stories about photographs often worked in radically different ways from those stories about paintings, with photographs posing a new set of problems for viewers. This essay is about how writers of picture stories explored those problems, and aims to uncover how and why paintings and photographs work differently within this genre of short fiction.
\end{abstract}

\section{Key Words}

Short stories; photography; painting; visual media; literary form; visuality; cartes-de-visite; stereoscopes; Victorian periodicals.

Date of Acceptance: 1 October 2020

Date of Publication: 25 October 2020

Double Blind Peer Reviewed

\section{Recommended Citation}

Potter, Jonathan. 2020. "Picture Stories, 1840-1860, or Problems with Photographs." Victorian Popular Fictions 2.2: 59-75.

ISSN: 2632-4253 (online).

DOI: https://doi.org/10.46911/BUWD1106 


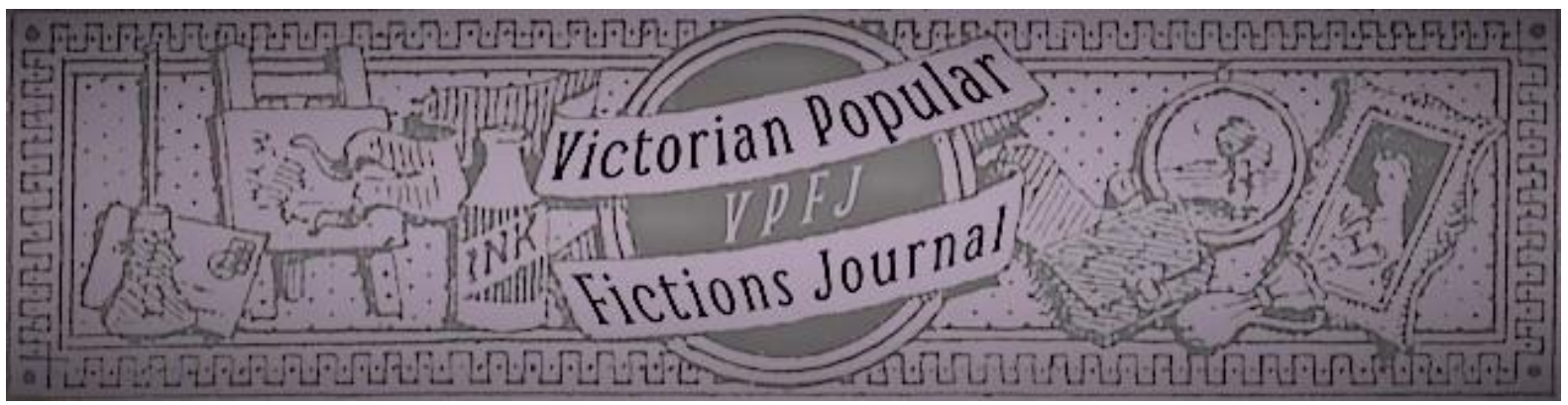

\title{
Picture Stories, 1840-1860, or Problems with Photographs
}

\author{
Jonathan Potter
}

\section{Introduction}

This essay is about a historical literary genre - "picture stories" - that made use of the literary form of the short story to do things with pictures. Form and content, two essential aspects of both literary texts and visual media, are core to how we understand literary-visual relations. Such relations are not clear cut but involve complex interactions between form and content on both sides, just as to "purify" media into categories of "word" and "image" is, as W. J. T. Mitchell (1994: 4-5) pointed out, to oversimplify the complex interactions between visual and verbal, and our history of literary-visual culture has grown to reflect this. ${ }^{1}$ The picture stories I identify in these middle decades have been largely overlooked in this history, but offer fresh insight into the complex relations between words and images within the popular culture of the period.

In this essay I use the term "picture stories" as a collective term for a largely overlooked form of short story that was popular in the periodicals of the 1840s, 1850s, and 1860 s, and which is characterised by the central role of a picture, without which there would be little or no story at all. These stories featured in periodicals publishing fiction aimed towards middle- and lower-class readers, such as Ainsworth's Magazine, Chamber's Edinburgh Journal, Bentley's Miscellany, and Sharpe's London Magazine of Entertainment and Instruction for General Reading, with titles usually making the genre obvious: e.g. "The Story of a Picture" (1842), "The Fatal Picture" (Elder 1843), "The Adventures of a Picture" (Medwin 1843), "The Unfinished Picture: A Reverie" (Kenney 1845), "The Lost Picture" (1853), "The Unowned Picture" (1856), and "Memoirs of an Old Picture" (1859). Although these stories are about images, in most cases they were not illustrated but were printed only as texts. For this reason, the primary questions they raise are not about their relation to actual images, but about the virtual images presented textually in their narratives.

${ }^{1}$ Scholarship on Victorian literature and photography alone is a rich field. A few well-known examples include Nancy Armstrong (1999), Daniel Novak (2008), and, more recently, Jennifer Green-Lewis $(1996 ; 2017)$ and Owen Clayton (2015). Elsewhere, scholarship has more broadly considered visual-literary relations, as in, for example, edited collections from Luisa Calé and Patrizia Di Bello (2010), Colette Colligan and Margaret Linley (2011), and Nicoletta Leonardi and Simone Natale (2018). 
As a genre, picture stories have not received much scholarly attention, but Diana E. Bellonby (2012) and Deborah Manion (2010) have made significant contributions in their explorations of the longer history of painted "magic portraits" across the nineteenth century. Taking the "magic portrait" of Oscar Wilde's 1890 novella The Picture of Dorian Gray as an emblematic example of a recurring trope, Bellonby and Manion both seek to examine the development of this trope across a wide range of texts throughout the Victorian period. Bellonby (2012: 1), like me, considers "magic portrait" stories as a distinct, though hybrid, genre "that depends on ekphrasis [...] and is defined by the practices of translating images through words and of narrating aesthetic philosophy through the formal body of prose fiction." Manion (2010: 16), however, considers "magic portraits" more a trope than a genre - a kind of narratological technique employed in a range of genres but which retains an identity as "a narrative vehicle in its own right with unique stakes and significations." From these differences in definition, Bellonby and Manion take quite different approaches, with Bellonby interested in the philosophical and aesthetic history of the genre and Manion interested in theorising the trope's "charged exchanges" between images and characters who view them. Despite their differences, certain convergences emerge. First, both studies illuminate the adaptability of the genre (or trope) for subversion, as well as reiteration, of dominant heteronormative narratives, not just in Wilde's famous novella but in a host of other fiction by writers such as Margaret Oliphant, Vernon Lee, and Ouida. Secondly, both studies draw attention to the appearance of the "magic portrait" in novels as well as short stories, and both Bellonby and Manion give detailed readings of Charles Dickens' Bleak House (1853), alongside other novels such as Wilkie Collins' The Woman in White (1859) and George du Maurier's Trilby (1895).

In this essay, I aim to add to this work by both broadening and narrowing the focus of enquiry. I intend to narrow the historical focus to the period from the start of the 1840s to the early 1860s, just after what Bellonby calls the "first wave" of stories in the 1830s. My purpose for this is twofold: firstly, because the short fiction of this period has not yet been fully examined, having been surveyed only briefly in Bellonby's and Manion's studies, and secondly because the added complication of photography increases the value of understanding the genre in this period. The addition of photography is where my investigation in this essay broadens the scope of enquiry compared to Bellonby's and Manion's work. Although Manion $(2010 ; 2016)$ does examine the role of photography (and media) via Thomas Hardy's photographic picture story, "The Imaginative Woman" (1888), both Bellonby's and Manion's studies focus almost exclusively on painted portraits. It is also worth noting that not all picture stories feature magical or supernatural elements - indeed, to encompass this, Manion uses a broad definition of "magic" to include psychologically uncanny experiences. To reflect my broader conception of the genre within the mid-century context and to more clearly include stories without explicitly magical elements, I take the cue from the titles of the stories in question to call these "picture stories" rather than "magic portrait stories." However, I am indebted to Bellonby and Manion for their work in uncovering and theorising the broader historical context of the genre.

Although in this period many of the "pictures" in picture stories are paintings, a subsection of picture stories forms its plot around technologically produced images - primarily photographs and stereographs, but also slides for microscopes and magic lanterns. These picture stories often work in a different way from those centred on paintings - most notably in how the image is interpreted. A key question, then, is how and why do paintings and photographs work differently even though they appear within the same genre? In this essay I make two key points. First, I begin by observing that short stories in this genre operate differently from longer forms of fiction which, on the face of it, seem to share their concern 
for images. Secondly, and forming the bulk of my argument, I hope to demonstrate how, within short picture stories, those stories that focus on photographs are radically different from those that focus on paintings.

\section{Conventions of the Genre}

The picture stories I investigate here are short stories that employed the brevity of the short story format to construct complete narratives around pictures. In these short stories, pictures act as the central conceit around which the entire narrative is built, a role often indicated by the central position of the word "picture" in the title. This specific use of pictures in fiction is particularly suited for the short story form. Pictures shape the narrative, but they are not meta-pictures; that is, they are not pictures presented to the reader outside of the fictional world, but are explicit objects open to interpretation from the story's characters. That, in fact, is usually the point - these stories are commonly more interested in the subjectivities of new forms of looking rather than in formal experimentation inspired by new visual media. This can and does occur to some extent in novels like Bleak House and The Woman in White where pictures might act as plot devices, but in a complex novel pictures rarely have a central role and are usually only one part of a much broader narrative fabric. In many of the short picture stories published in the periodicals of the three decades after 1840, the whole narrative force stems from the role of the picture. The short story form allows writers to attend to pictures in a single-minded way that would be made difficult by the more diverse interests of a novel. Such singular focus enabled writers to make particular points or raise particular issues surrounding the creation, viewing, and reception of images that would risk being lost among the competing narratives, voices, and perspectives of a more complex narrative structure. As will be seen, most often this attention raises interesting questions about the hermeneutics of images, about what Manion calls the "charged exchanges" between an image and its viewer. This is especially true for the period immediately after the introduction of photographs when traditional image-viewer relations were called into question by this new pictorial form which apparently held an altogether different relation with reality.

Beyond their focus on pictures, picture stories of the mid-century share a number of genre conventions that draw them together into a recognisable genre. Most picture stories are first-person narratives, often recounted in speech. Many of them are set at some point in the past (sometimes the distant past as a recounted legend, more commonly at a vague indeterminate point during the narrator's lifetime, but rarely at a very recent or present moment). Many of them are set either wholly or in part abroad, most commonly in Germany or Italy. Many of them end with a central character dying suddenly and some, especially those involving paintings, include supernatural elements such as demons, devils, and ghosts.

Of the picture stories about painted pictures, the picture is almost always a portrait that has some emotional or spiritual power over the artist or observer. A typical example is "The Story of the Unfinished Picture: A German Artist's Tale" (Hooton 1846), which recounts the tale of a poor artist the narrator knew in Heidelburg [sic]. The artist makes a pact with a demon/devil figure: if the artist can finish his next painting within a year, the demon promises to buy it from him and make him wealthy, but if he fails to complete it in a year, he is bound to "go to the woods" with the demon. As the year progresses, the artist works obsessively on a painting described as both beautiful and terrifying: the portrait gives a first impression of "the highest conceivable manly beauty [...] but as you continued to gaze, that feeling grew imperceptibly into one of fear [...] and at last, into a sense of utter dread and horror [...] like the blighting presence of a demon" (Hooton 1846: 350). Gradually the artist wastes away as 
the painting grows ever more beautiful and lifelike, as if the painting were "the living palpable reality, and he, the workman, only such a dim animated shade as human art and earthly colours might produce" (351). Ultimately, he fails to finish his painting within the appointed year and the demonic figure returns, pays the artist's family regardless, but takes him away, never to be seen again, although the narrator mentions a legend about a ghostly figure that continues to work on the painting by night. Other stories riff on the theme of a painting that exerts mesmerising and devastating power over its creator. For example, the eponymous painting of "The Veiled Picture: A Tale of the Fine Arts" (1833) is kept veiled because of the artist's unfulfilled love for its subject (both artist and subject die at the end). Similarly, "The Unfinished Picture: A Reverie" (1845), a parody of the trope, has the picture speak directly to an initially fascinated but restless and increasingly disinterested narrator who forgets a key part of the story before shrugging it off and saying that he will get an article for Bentley's from it anyway.

There is often a sense of writers revisiting a lost era when one reads picture stories about paintings. The stories tend to be set in gothic locales, told via oral traditions, and, crucially, in various ways they all mythologise painting, an old-fashioned visual medium. This turn backwards seems odd, in an era of photographs, stereographs, microscopes, and so on. In this new era, there would seem to be easier ways to achieve a hyper-realistic image than forging a pact with the devil, and new technological methods were likely at the forefront of readers' minds. Indeed, descriptions of the latest scientific and technological discoveries in photography and so on fill the pages around these stories. Alongside "The Unowned Picture" (1856) in Sharpe's London Magazine for instance is a fictionalised account of "Life in a Drop of Water" inspired by microscopes and an article about the "threatened extinction of ghosts" due to "the march of intellect, railways, gas, and the new police" ("On the Threatened Extinction of Ghosts" 1856: 175-8); immediately following "The Lost Picture" (1853) in The London Journal are sections on "Science, \&c" and "New Inventions." Many venues for short fiction had regular features about scientific and technological developments. Ainsworth's Magazine, for example, reported on the annual meetings of the British Association for the Advancement of Science, Chamber's Edinburgh Journal had a feature entitled "Exhibitions Illustrative of Science and the Arts," and Sharpe's London Magazine included regular features on "Curiosities of Science" alongside essays on specific events or advances (e.g. "The Telescope" 1846; "Every-day Essays on Science" 1848). Bentley's Miscellany was less interested in scientific advancement but nonetheless featured occasional essays on entertaining aspects of science (e.g. "Facts and Fallacies" 1847). Within this context, short stories provided a method of exploring everyday human interactions with new scientific and technological developments and, as I argue in this paper, a notable feature of picture stories about photographs is their interest in viewer response. Published in a context of scientific and technological development, the sense of a bygone era in picture stories is less a conventional sense of nostalgia than a sense of fairy-tale disconnection or technological uncanny in which the leitmotif is media innocence.

In saying these stories utilise and convey a sense of "technological uncanny," I am drawing on Tom Gunning's (2003) description of the term in his discussion of the transitional technologies of the fin de siècle. Gunning suggests that part of the astonishment at new technologies "comes not simply from unfamiliarity" (relating to more traditional Freudian meanings of "uncanny") but stems from a "utopian dimension that imagines a future radically transformed by the implications of the device or practice" (2003: 56). It is the tension between this kind of aspirational fantasy and the future actually realised which makes the relation between old and new technologies so interesting here. In picture stories, we have a new technology - photography - which contains the utopian promise of transformation made 
by all new technologies, in this case stemming from an apparently radical intervention into how humans see and record the world around them. But we also have an old technology painting - presented in pointedly historical settings and often with a markedly non-realist (usually gothic) style. The effect is that readers are reminded of a time when painted portraits still held their original promise - the apparent magic of mimesis - which has since dulled and has seemingly been superseded by photography. At the same time as readers are reminded of painting's faded promise, readers are also reminded that the new future imagined in the arrival of photography is likely to itself one day fade and be superseded by something else, since this is the way with all technological innovations. The effect is thus double: on the one hand, readers are reminded of the once-credible mimetic claims of painting, which generates nostalgia as well as a sense of critical superiority; on the other hand, the reminder of the rupture between once-credible technological promises and the now too-familiar, too-mundane reality, is uncanny since it both defamiliarises the mundane (painting recaptures some of its faded magic) and pulls the unfamiliar and fantastic back into the realm of the mundane (it implies that photography's promise will succumb to the same fate as painting's now-faded promise). This interplay of technological narratives provides the background against which we can begin unravelling how the different media are treated within picture stories.

\section{Photographs in Picture Stories}

A subsection of picture stories, which appeared more predominantly in the late 1850s and early 1860s, featured photographs and stereographs as their central conceit instead of focussing on paintings. Stories such as "Her Face" (Collins 1858), "How One Fire Lit Another; Or, The Mischief Done by My Photograph" (Ouida 1860), and "In a Stereoscope" (Walter 1863, repr. 1864), all reposition the genre - placing it in a contemporary setting with up-to-date media, but retaining elements of an oral narrative tradition - most obviously, the first-person narration from a minor character recounting a past experience. ${ }^{2}$

Photographs tend to operate differently from paintings within picture stories. Paintings, especially in stories of the $1840 \mathrm{~s}$, tended to be treated as externalised entities distinct from the entity of the painter or observer (in one story, an extreme case, the painting literally speaks, becoming a character in its own right). The painting usually has a unique, close relationship with a specific character (an observer or the painter), but acts upon them against their will: the painter is forced to veil a painting of the woman he loves because he cannot get rid of it nor bear sight of it, until his untimely death, and then, when the painting is presented to his love, she too dies ("The Veiled Picture" 1833); or the painter, spellbound by a deal with a demon, is unable to stop painting even as his body wastes away (Hooton 1846); or the painter is a humble monk who wishes to be left alone, only to be inadvertently discovered by the

2 This is not a feature of all picture stories but is a common trope within the genre. In "The Photograph," this is subtle but such asides as "(I refrain from giving full names as my story is a true one)" (1859: 226) work to convey the idea of an oral recounting. The ending of "In a Stereoscope" actually implies a clear relation between audience and teller: "your uncle talked in his sleep, after seeing your stereoscope" (Walter 1864: 89), written not as speech to a third party but as narration to the reader. Ouida's 1860 story, which is longer, does this with greater intricacy, beginning with the situation of the narrator - "I belong to Lincoln's Inn, if you wish to know" (423) - and gives frequent asides and addresses to an imagined audience: e.g. "Trevelyan, au contraire - though I can witness that his strong muscles tell in a slashing stroke through a heavy swell [...] - is graceful and well knit [...] and his face - Well, if you had seen its proud regular features, veloutés eyes, and beautiful mouth, it would probably have haunted you, mademoiselle, as, one way or another, it has haunted a good many" (423). 
famous artist Rubens who comes across one of his paintings, forcing him to destroy all his work and cast his brushes into the river to renounce his art ("The Unowned Picture" 1856). Conversely, photographs (including stereographs) tend to act in a more intimately psychological manner and a key distinction between paintings and photographs in Victorian picture stories is the way in which the observer reacts to the image.

Compare, for example, the narrator of "The Unfinished Picture: A Reverie" (Kenney 1845 ) with the narrator of "Her Face" (Collins 1858). In both stories, a male spectator is enraptured unexpectedly by a chance glimpse of a portrait - one painted, but in a way that makes it clear it comes "from life" (Kenney 1845: 411), and one photographic. In the first story, Kenney's "The Unfinished Picture," the narrator enters a "rattle-trap shop" - a class of shops denoted by their chaotic, jumbled assortment of objects - and is "glancing from object to object" when his attention is "fixed" by an unfinished painting of a woman (411). The narrator buys the painting and stares fixedly at it before losing interest even as it speaks to him - in keeping with a trend in the genre of male spectators ignoring the voices of women. ${ }^{3}$ He shows no interest beyond a superficial appreciation of the painting's beauty. In the second story, Collins' "Her Face," however, the narrator's chance glimpse of the photograph is followed by a chance glimpse of the woman, whom he obsessively pursues and to whom he eventually becomes engaged (via her father as intermediary since she actively avoids him).

Both stories use the contrivance of a chance glimpse of an image, and both feature male onlookers consuming women's images while actively ignoring their voices. They are dissimilar, however, in the narrator's consumption of the image. In "The Unfinished Picture" (Kenny 1845), the narrator remains aloof and emotionally disconnected from the picture, even stopping listening entirely during a crucial part of the picture's story so that narrator and reader are left with an incomplete narrative. In "Her Face," on the other hand, the narrator's response to the image - and to his subsequent glimpses of the image's real-life subject - is presented in ways that inform readers about his psychology and personality. The same is true more generally: whereas stories centred on paintings tend to treat the image as externally connected to the observer, photographic stories tend to treat the image as a nexus for internalised, psychological meaning. In other words, photographic images in picture stories reflect the observer's inward character as much as they represent another's outward appearance.

In these stories, paintings act as external forces upon observers, photographs as mirrors that reflect the observer's memories, dreams, fears, and desires. In Ouida's 1860 short story, "How One Fire Lit Another; Or, The Mischief Done by My Photograph," a group of holidaying gentlemen (including the first-person narrator) vie for the affections of a young lady, Florestine, who is travelling with her father in Switzerland. Towards the end of the story, the narrator, who is a keen amateur photographer, photographs Florestine without her knowledge (earlier in the story she forbids him from taking her picture). She is unimpressed by the portrait but gives one of two copies to her intended suitor, Royston, upon his request. When one of Royston's rivals brags that he is to marry her and reveals the second copy of the portrait, Royston assumes her infidelity. He acts coldly to her over breakfast the next morning - but does not mention his complaint - before they part ways, and they do not see each other

\footnotetext{
${ }^{3}$ As well as Kenney's "The Unfinished Picture: A Reverie" (1845) and Collins' "Her Face" (1858), examples include: "The Lost Picture" (1853), in which a rector falsely accuses his wife of infidelity after he loses a locket containing her portrait and believes she has given it to someone else only to discover his mistake after her death; and "The Veiled Picture: A Tale of the Fine Arts" (1858), in which an artist recounts the story of his unfulfilled romance with the woman in his painting, although the woman in question does feature in the final part of the story - she goes mad following the artist's suicide and dies before her wedding to another man.
} 
again until a year later when, back in London, they run into one another by chance. Royston immediately asks her if she is married and she responds by railing clearly and powerfully against the men's bartering of her marriage (symbolised by the transactions surrounding the two photographic portraits):

I am no one's wife. You might know that. What right have you to portion me off to Lascelles, or to anyone else? What right have you to class me with the low-bred intrigantes or fashionable manoeuvrers who haggle for a wedding ring, and have taught you disgust for all our sex? What right have you to judge that I should marry for marrying's sake, take any man's name - the first that offered - and give myself for mere position when you know my love would never go -

(Ouida 1860: 540, emphasis in the original).

She stops short here and then, in a didactic tonal switch ("She did what I wish you would do sometimes," the narrator writes), she kneels and in a whisper ("like a little child sorry for a great fault, though, Heaven knows, the error lay on his side") enquires why he is angry with her (he still has not told her) (540). After Royston explains his sudden change of heart just before they parted in Switzerland, it is revealed that her father had given someone else the second copy of the portrait (and a promise of her hand in marriage) without her knowledge. She quickly forgives Royston (though not without reprimanding him for not trusting her) and they are then married at the story's conclusion.

A number of things stand out in Ouida's story. First, the photographic portrait is treated as a stand-in for the real person. Florestine is not given the opportunity to redress her suitor's false assumptions until much later, and, interestingly, she is consistently clear in her reluctance to be photographed, as though aware of its silencing effect. When she is presented with the portrait, she reacts with horror: "Oh! Mr. Temple what a shame!" (531). Despite acknowledging the quality of his photography, she feels "it is unpardonable [...] when I have always solemnly vowed never to be photographed" (531). She does not explain her aversion to photography, but the plot does appear to justify it. Secondly, in the way that a coin acts as a signifier of value to facilitate easy financial transactions, in Ouida's story the photographic portrait, as a signifier of the woman herself, facilitates and expedites the transactions of the marriage market. Instead of a complex social interaction involving both Florestine and (potentially) her father, the would-be suitor has only to speak to her father who then offers her photographic image as a token of the deal. This is made clear when the rival reveals his supposed engagement: he draws the second photograph from his pocket "and looked at it in the moonlight, curling his whiskers with a look of extreme triumph and contentment to think the original has been promised to him" (535). That complications arise from this expeditious transaction is a clear critique of its reductive reification - Ouida's story is clear that romantic happiness cannot be attained without the full, active participation of both parties: a photograph is not a stand-in for a wife. If, to twenty-first-century readers such a conclusion appears axiomatic, we have only to remind ourselves that, in Collins' story "Her Face," a similar transaction takes place without any redress. In Collins' story, the young woman is almost entirely omitted, with her photographic image and her father's bargaining sufficient for the narrator's happy denouement. In this context, Florestine's remonstration ("what right $[\ldots]$ ?") functions as a wider social critique.

As is clear from these examples, gender plays a significant role in picture stories: portraits are usually of women - and usually described in extravagant terms of beauty - and viewers are usually men. In some stories, pictures cause misunderstandings - in "Her Face," "How One Fire Lit Another," and "The Lost Picture," a woman's image (photographs in the first two and a miniature in the last) causes her to be persecuted to varying extents by a male spectator. In "Her Face," a man chances upon a woman's portrait in a photographer's window display and obsessively pursues her across London; in "How One Fire Lit Another," a 
woman's portrait leads to her being suspected of infidelity and abandoned by her lover; and in "The Lost Picture," a rector loses the miniature portrait his wife had given him while they were courting, wrongly accuses her of unfaithfulness which contributes to her tragic early death, and then finds the misplaced portrait many years later leading to his own death. The dynamic between female subject and male viewer varies in these different examples, but all are told from a male perspective.

If a picture could act as a silent, pliable surrogate for a real person, this silencing effect is an aspect of the fictional frameworks of the stories too. In "Her Face," the woman's voice is never presented, in "How One Fire Lit Another," although Florestine rebukes her lover she is very quickly shown to meekly forgive him, and in "The Lost Picture" the woman is presented as unfailingly subservient and devoted to her husband's wishes, leaving the narrator (her husband's friend recounting the tale to a second, framing, narrator) to eventually rebuke her husband on her behalf. Women are conspicuously visible, sometimes against their will, but they are often quiet and passive characters within the story (although there are, of course, exceptions). ${ }^{4}$

\section{Images as Objects/ Objects as Images}

For the male narrators and viewers, it is often difficult to disentangle the physicality of the photograph-as-object from the psychological response to the photograph-as-image. The close relation between "image" and "imagine" (they share an etymological root) is integral to the function of photographic images in these stories. Whereas paintings are externalised as objects, photographs are treated by observers as being spiritually or emotionally connected to their subjects. Seeing a painted portrait of a woman is not the same as possessing her photograph. Leslie Walter's story "In a Stereoscope" (1863), for example, builds its narrative as a dream that occurs when the narrator has fallen asleep after looking at a set of stereoscope slides $^{5}$ - each (almost certainly photographic) slide offering a glimpse, it seems, of another world. Except that this is not revealed until the very end - until that point, both reader and narrator are confused about the fantasy they find themselves in. At the end we get a glimpse of the slides as the narrator names them, thereby explaining the previous scenes: "the Spanish Girl," "Dressing for the Ball," the "Moonlit Balcony" (Walter 1864: 89). Identifying the slides in this manner then allows the reader to retrospectively decode the narrative, deconstructing how the narrator had imaginatively encoded the images to create a fantasy. The fantasy is primarily erotic in nature, such that the narrator tells the children to "never tell your aunt what nonsense your uncle talked in his sleep, after seeing your stereoscope" (89). Up until its conclusion the story is dominated by a hermeneutic struggle with the photographas-image, with the narrator lost in the fantasies conjured by the images. It is only at the end, with the final realisation that these are slides and thus only flat material objects, that normal reality is reinstated.

There is, however, a certain looseness in how this effect is applied using various media and technologies. In Wilkie Collins' story "My Black Mirror" (1856), for example, the eponymous mirror is an explicit, visible, tangible object, but it presents the narrator with moving, speaking images on any and all subjects. If we try to place the mirror somewhere on

\footnotetext{
${ }^{4}$ In "The Photograph" (1859), for example, the subject is male and the spectator female - the gazing woman dies while the gazed-upon male love interest lives.

${ }^{5}$ The stereoscope, invented by Sir Charles Wheatstone in 1838 and adapted and popularised as an optical toy by Sir David Brewster in the 1850s, was a device that used the principles of binocular vision to create a sense of three-dimensional depth from flat images, usually photographs.
} 
the spectrum from a painting (an object to be looked at) and a photograph (an object to be looked through), then at first reading it seems as though the mirror is closer to the latter than the former. The mirror transports the viewer who asks it where he should go on his holiday. Looking into the black mirror, he sees himself struggling with various potential destinations through its polished black surface. As in "In a Stereoscope" (Walter 1863), the images have a present-tense urgency, and resist explanation: "I am in the presence of two cheerful slovenly waiters, with two flaring candles [...] Where am I, now that there is plenty of light to see by? Apparently in a banqueting-hall [...]" (Collins 1856: 170). The scenes are often bewildering - in one, for instance, the narrator struggles to converse with a waiter who keeps switching languages: "All through dinner I try hard to make him talk the same language that I do, yet [...] I never succeed. What is the meaning of his playing this game of philological see-saw with me? [...] I cannot explain it" (170). Finally, the narrator is swayed by a happier scene of sailing along the south English coast and the story ends. In format and in tone, Collins' story is similar to "In a Stereoscope," in that its scenes sometimes unfold without a clear logical connection leaving the narrator (and reader) confused, but Collins' story is different in that it primes its readers for this. Whereas "In a Stereoscope" refrains from mentioning the visual media until the very end (apart from the title, of course), Collins opens with an upfront discussion of the visual media in question, even advising readers to make their own black mirrors from polished coal.

In the first half of Collins' story especially, the text recursively comes back to the notion of surface. The appearance of the first vision is carefully described:

A cloud rises on the magic surface - rests on it a little while - slowly disappears. My eyes are fixed on the cannel coal. I see nothing, hear nothing of the world about me.

The first of the magic scenes grows visible. I behold it, as in a dream. Away with the ignorant Present. I am in Italy again. (170)

The narrator sees himself (or potentially herself - gender is not specified but can be conjectured) in the scene as though viewing from outside himself, and the scenes are framed by questions as a form of meta-narrative: "Show me my sitting-room. Where did I dine, and how, on my first evening in Austrian Italy?" (170). In one way, the technique is reminiscent of how we might talk about photographs ("I am in Italy" sounds a lot like someone pointing to a photograph: "Here I am at school," "This is me at home"). However, whereas with a physical photograph, the phrase "Here I am at school" would gesture away from the physicality of the object (the surface, the flatness, the smallness of the photograph) and towards its subject, in a literary context where no such physicality exists, the phrase first draws attention to the idea that we are looking at an image in the first place. This is a photographic technique that Jennifer Green-Lewis (2017: 108-9) identifies within Victorian novels: the present-tense first-person narrative stance ("Here I am at...") used to create "album scenes." Yet whereas in a lengthy novel such as David Copperfield, occasional instances of the technique create a subtle nostalgia effect, in a short story like Collins' "My Black Mirror," the effect is different. Because the medium has been foregrounded, and because the entire narrative makes use of the technique, the transparency of the textual image (the sense that we are looking directly at its subject) is disrupted by a sense that this is an image to be looked at. Indeed, the purpose here is to draw attention to the act of looking itself.

It might seem a bit of a truism to think of the photographic surface as a transparent window onto its subject, and so it is. Photographs are often experienced as an ultra-realist illusion - looking at a photograph of a lake, it is easy to forget the medium and see only the lake - but it is also true that, as scholars have shown (e.g. Novak 2008, Bear 2015, and 
Clayton 2015), since the early history of photography people have been aware of the limitations of photographic realism in a multitude of ways. The surface of the photograph might often be overlooked (or rather, looked through), but the photograph remains only an object, complete with its own set of boundaries, however well disguised these might seem. Green-Lewis observes that modern viewers continue to fall into the realist trap, noting of the canonisation of certain Victorian photographers and photographs: "That canon of images to which we are so attached reveals as much or perhaps more about the intervening century and a half of readers as it does about the original seconds photographed" (1996: 16). This is the precise observation that lies implicit in many of the mid-Victorian picture stories that utilise photography or other technologically produced images. The narrative tension so often stems from the tension within the image itself, between its supposed transparency and its real function as an object to be read. As readers of these stories, our attention is not directed to the images themselves but to the reactions of the characters looking at the images.

We can see this in Ouida's story "How One Fire Lit Another," in which the misinterpretation of a photograph causes a rift in a budding romance. The male suitor's misreading of the photograph is eventually corrected but, as with "In a Stereoscope," the central tension in the narrative derives from the way the image is read. In Ouida's story, the viewer attributes such meaning to the photograph that it ceases to be simply an object, but acts as a nexus of emotional and social value. The photograph is not merely an object until the actual person who has been captured by the lens (and it does read like an act of capturing) is finally given opportunity to reassert their autonomy - up until that point, the photograph acts as a transactional signifier for the person, effectively removing their participation in transactions about them. Once the person has been able to reassert their autonomy (and undo the damage caused by the transactional use of their image), the photograph reverts to being simply an object, to being only an image. Ouida's story makes use of photography, but it is not formally photographic - just as the genre generally makes use of pictures but is not primarily pictorial in form. Ouida does not use the present-tense first-person narrative stance that Green-Lewis (2017: 109) has identified. Rather than positioning the central story as the picture with a framing meta-narrative ("Here I am at..."), in Ouida's story the picture is positioned as an object within the narrative to enable readers to look at its social and emotional effects and functions, but without close attention to its actual image. ${ }^{6}$

For the characters in these stories, paintings generally retain more of their object-hood than photographs; they are less susceptible to fallacious assumptions of truth. The spiritual connection between painting and artist in, say, "The Story of the Unfinished Picture" (Hooton 1846), is only between painting and artist and relies on forces beyond simple human error. Other characters respond to the painting's beauty and sense of malevolence, but they are not affected in the deep, mesmeric way it affects the painter. Similarly, in "The Unfinished Picture: A Reverie" (Kenney 1845), the spectator is initially moved by the painting but quickly grows bored of it - despite the profound effect it appears to have once had on its artist. The intractable object-hood of paintings, the unavoidable sense of mediation, is perhaps because the painted surface, with its brush strokes (no matter how well disguised) and careful design (even the composition has something inescapably unreal about it, something that hints at artistic invention rather than the contingent multiplicity of reality), is more apparent than the photographic surface which seems as clear as glass and, even when

${ }^{6}$ This is despite the use of the terms "picture" and especially "sketch" being widely used in other contexts to denote a literary text - e.g. Sketches by Boz, Pictures from Italy, The Irish Sketchbook, etc. This usage is implied in, for instance, Kenney's "The Unfinished Picture: A Reverie" in which both the picture and the story are left incomplete. However, in most of these stories, the term "picture" primarily denotes the picture within the story, not the story itself. 
carefully staged, cannot fully avoid all the small contingencies that make up the real world. The paintings in these short stories are treated, not as socially neutral "Essential Copies" of a pure visual domain (as in Bryson's 1983 account of the "natural attitude" in art history), but as purveyors of social values. In many of these stories, this social significance comes at least in part from the artist as a mediator. Photographic images in these stories also have social meaning but characters tend to treat them as though that meaning pertains to the person or thing in the image itself, almost as though the photograph provides direct access to the reality. Whereas the painter's role is often considered, no one looks to a photographer as the mediator of meaning. It is as though photography, through its machine eye, has achieved the realist holy grail: a pure image unaffected and untainted by human mediation.

This sense of machine-made purity presented new problems, both for photographed subjects who might be viewed in unexpected ways beyond their control, and for viewers who might long for a greater emotional or social attachment to the image. To this end, the human mediation in painted pictures bears a striking resemblance to the burgeoning popularity of hand-colouring photographs in which machine-made objects are endowed with emotional and pseudo-spiritual properties. ${ }^{7}$ Viewers of photographs also had the problem that, if one did not treat it as a single, dislocated representation of its subject as one might with a painting, then one risked becoming entangled in a mesh of misunderstandings. Picture stories centred on photographs do not have the surface-mediated surety that the picture is merely - only - an object, but must first negotiate the image before they can, potentially, deal with the object.

\section{Pictures and Objectivity}

Paintings in these stories can sometimes function like clues. As Franco Moretti (2000) points out in his work on clues in late-Victorian detective fiction, clues operate as encrypted references to criminals: they are there to be decoded by the detective and (possibly) the reader. In "The Unfinished Picture: A Reverie" (Kenney 1845), for example, the narrator chances upon a painted portrait and then listens as it recounts a tale to him; the painting exists to retell a story about past events (albeit via the fantastical means of its subject speaking). This is true, too, for "The Veiled Picture" and "The Uncovered Picture" where paintings are decoded as clues to some secret (the hidden talent of the cloistered artist and the heartache of the artist, respectively).

These portraits perform similar roles to that of the portrait of Oliver's mother in Dickens' novel Oliver Twist (1839) or the portrait of Lady Audley in M. E. Braddon's novel Lady Audley's Secret (1862), which also act as plot devices. As Nancy Armstrong (1999) has pointed out, in Oliver Twist the portrait triggers Mr. Brownslow's memory, leading him to seek corroboration and, eventually, solicit oral testimony as more concrete evidence of Oliver's parentage. Similarly, in Braddon's novel the painted portrait of Lady Audley provides a clue to her bigamy when her first husband, George Talboys, sees it and recognises her, which then sets forth a series of events leading to her discovery via incriminating letters and handwriting analysis. The memory responses of Brownlow and George Talboys are only minor parts of a larger process through which the truth is discovered - the primary role of these portraits is only as a small clue that starts the process of detection.

7 Observing the popularity in women's periodicals of instructional articles on hand colouring photographs, Patrizia Di Bello (2007: 72-4) observes how women's hands were seen to endow machine-made objects like photographs with emotional, affective power. Similarly, Jesse Hoffman (2014) describes Dante Gabriel Rossetti's hand-colouring of photographs as an attempt to control his feelings surrounding the image. These examples demonstrate the acute awareness about the affective power (and viewer response) involved in photographs, and the desire to control or shape this power. 
Photographs in picture stories, however, tend to invert this function: instead of being decoded to say something about the world around the viewer, they are encoded by the viewing-character to say something about the viewer himself (it usually is a him). Whereas a clue is decoded objectively - corroborated by other evidence obtained separately and perhaps by different people, in order to say something about external, objective reality - glimpsed photographs create impressions that are often pointedly uncorroborated. In fact, the subjectivity of the response is the chief value ascribed to the image-object. In stories like "Her Face," "How One Fire Lit Another," "In a Stereoscope," and "The Photograph," photographs are prone to chance interpretations that then lead to unexpectedly strong viewer responses. The primary characteristic of the photograph is that characters encode the image with subjective meanings in a less self-conscious way than with painted images; they have fallen victim to the realist fallacy, imagining that their imposed meanings are actually objective facts. We can see this in "Her Face," and "How One Fire Started Another," where women's portraits are problematically encoded by male narrators. Stereoscopic slides, too, are imaginatively encoded in "In a Stereoscope," and in "The Photograph" a female protagonist emotionally encodes photographic stereographs of her fiancé (less problematically since she not only has his consent but he actively encourages it).

The short story "The Photograph" is an especially interesting example because the story actually exists in two forms: one with a painted picture ("The Altered Picture" 1854) and one with a stereoscopic photograph ("The Photograph" 1859). ${ }^{8}$ Both versions follow the basic narrative of a young woman named Alice whose fiancé (Edward in "The Altered Picture," James in "The Photograph") is a sailor and goes on a long and dangerous voyage after which they will be married. Both versions focus on Alice's anxiety about her fiancé but, in "The Altered Picture" Alice's fiancé gives her a painted portrait to remember him by, whereas in "The Photograph," he gives her a stereographic photograph. In "The Altered Picture," just before her birthday Alice has a supernatural dream about her fiancé's ship wrecking in a storm. The dream turns out to have happened at the exact moment that his ship really was wrecked, and after hearing news of his death, a grief-stricken Alice has her portrait of him altered to include him holding a small locket with her portrait and an image of his ship in the background. The picture thus becomes a visual narrative about the doomed romance and the supernatural dream - in other words, it acts as a clue. In "The Photograph," on the other hand, Alice is given a photograph of her fiancé to look at through her stereoscope and uses it to comfort herself during his long absence. During a children's birthday party, a magic lanternist, having run through a sequence of ghost images, projects James' image onto the screen as a joke and Alice, seeing him as a ghost, collapses dead, only for the real James to return unharmed. In the second version the photograph of Alice's fiancé is not described in close detail nor is it a fixed image but shifts across media technologies. ${ }^{9}$ The painted version, by comparison, is much more substantial as an object. The story in "The Altered Picture" is written as a reconstruction from the final, altered portrait. It begins with the first-person narrator looking at the painting and describing it in close detail before recounting its legend - the painting exists as a physical relic of Alice's story which is located

${ }^{8}$ The earliest printing of "The Photograph" that I have found was in the July 1859 issue of Sharpe's London Magazine of Entertainment and Instruction for General Reading, with a later reprinting in the September 1859 issue of the Ladies' Cabinet of Fashion. In my discussion of the story in Discourses of Vision (Potter 2018), I was unaware of the earlier printing in Sharpe's so this stands as a correction. Similarly, Leslie Walter's "In a Stereoscope" was published first in The London Reader: Of Literature, Science, Art and General Information (October 1863) and then in Sharpe's London Magazine of Entertainment and Instruction for General Reading (August 1864).

${ }^{9}$ I have written more on the intricacy of these different modes in chapter 6 of Potter (2018). 
by way of the clothes in the painting as sometime in "the early part of the last century" ("The Altered Picture" 1854: 380).

Across the genre, the physical presence of paintings is reinforced by their formal presentation within the text. As in the two versions of "The Photograph," painted images are generally more likely to be described - and in greater detail - than photographic images and, conversely, readers are more likely to encounter the real-life subject of the photograph than they are the painting. In fact, the lack of description of photographic images is a striking feature of these stories. For example, even in the most explicitly misogynistic of these stories, Collins' "Her Face" (1858), the opening account of the photograph focuses primarily on the narrator's response, rather than indulging in the kind of close, perhaps sexualised, detail of the female subject which modern readers accustomed to the male gaze in media might expect. The viewer clearly does fixate on her appearance, but as readers we are presented with his fixation:

Twas the sweetest face imaginable - and the most feminine. I could read in it - for by our faces, our gestures, our attitudes, our manner of dressing, and fifty other external indications that we have not the least idea of, we divulge continually all sorts of mental characteristics that we think our neighbours know nothing about, nay, that we ourselves perhaps know nothing about; - I could read in the face before me, I say, an ignorance of evil, a good sense and kindness of heart, that made me long to know the possessor of such a countenance.

(Collins 1858: 258)

Collins' narrator gives away very little objective detail about the woman in the photograph we do not know even basic details like her age or the colour of her hair, for instance - but exults in his own ability to "read" the image. This is overtly psychological too - he describes being "haunted" by her face, seeing it "through everything I looked at" (258).

The photograph in Collins' story is displayed in a shop window alongside an "Ethiopian singer," a "clown," an "itinerant pastry-vendor," and "a member of the Metropolitan Police Force" (258). The display resembles the common manner of displaying of cartes-de-visite, ${ }^{10}$ and indeed, cartes-de-visite brought to the fore similar issues of gender and class. Rachel Teukolsky (2015: 467) describes the real-life scandal caused by cartes of the courtesan Catherine Walters which some writers even complained were "pornographic," despite relatively modest costumes. According to Teukolsky, the level of alarm and the popularity of such images suggest "that the display of the female body, while seeming to mute the female figure into a disempowered and objectified visual commodity, in fact intimated to Victorian viewers a kind of sexual license and cultural dominance" (468). Thus, Teukolsky writes, "a woman on view might claim an aggressive, illicit power over her spectators; she was, in a sense, both purchaser and purchased" (468).

In this sense, it is possible that Collins' story, right at the very start of the craze for cartes, is playing with a cultural trope of male powerlessness in the thrall of a woman's enchanting beauty. I can imagine an argument that, by presenting such a trope from a firstperson perspective, Collins foregrounds the agency of the enthralled male gazer and thereby highlights the problematic nature of his ensuing pursuit of the woman whose image has entranced him whilst also showing the power of the image over him. Indeed, it is perhaps questionable how much Collins' story buys into the veracity of the narrator's interpretive skills. He claims, for example, to see "almost excessive cleanliness and neatness" from a single "glance" at details such as "the evenness of her braided hair, at the tying of her bonnet

${ }^{10}$ As Rachel Teukolsky explains, a carte-de-visite was "a small photo, usually a portrait, mounted on a card of approximately two-and-a-half by four inches" and "was cheap, easily reproduced, and existed in multiple copies" (2015: 464). Millions of these were sold in the 1860s. 
strings, and at the arrangement of her dress" (Collins 1858: 258), and such claims are neither countered nor corroborated in the ensuing narrative. However, without more information about the actual woman, the narrator's suppositions are left unopposed and, for want of anything better, stand for what constitutes "truth" in the story. As readers we might be sceptical about his "reading" but the story itself does not explicitly treat it as problematic, unlike the erroneous suppositions of the male narrator in Ouida's story, for example.

In Ouida's story, the male viewer must deal with the confrontation between his false assumptions (encoded in the image through his presumptive gaze) and reality - it is only when he realises the gap between the two that he can progress to his happy ending with his beloved. He is not anxious about hiding his reaction to the image, but only because he does not realise it is not the clue-like signifier he thinks it is - he does not realise it says more about him through his reaction than it says about the world around him. The narrator on the other hand (who is also the photographer) does seem to be at least semi-aware of the emotional encoding of the image. When Florestine leaves Switzerland, the narrator goes to find Royston who is missing from the farewell. He finds him "standing on the hearth, stamping into a thousand pieces - as if he would crush out with it all memory and all passion - Florestine's photograph" (Ouida 1860: 536). The image has been endowed with emotional projections from the viewer, much like the image in "Her Face," and Royston now seeks to "crush out" that emotional attachment. The narrator's awareness of this creates a critical distance between the reader and Royston's psychosexual reading of Florestine's image. Given this distance, the violence of Royston's action is striking, especially in light of his utter inaction in confronting or communicating with the real Florestine. The image, in this way, seems to have a further function in providing a private outlet for otherwise hidden emotions.

Although (or perhaps because) the narrators of these stories often treat the interpretation of images with uncritical acceptance, they are also often shy about being seen themselves. In an explicit concern for what may have been revealed, the male narrator of "In a Stereoscope," having had a fairly innocent but erotically charged dream, is anxious that his wife not hear of it. Likewise, the narrator of "Her Face" is overtly anxious to avoid scrutiny from others - at one point even fleeing the scene because he fears himself open to observation. Lurking outside her house, he describes the oppressive observation that forces him to flee:

observed by the general dealer whose station was at his shop-door; observed by the lady who retailed oysters at the corner; observed by the policeman who came to the other corner, and took up a position there apparently with the sole object of observing me. Observed - why even the milk-woman had her eye upon me, and she spent a good deal of time in that street when she had evidently a large practice.

(Collins 1858: 260)

His sensitivity might hint at a sense of transgression or impropriety in his behaviour but if so it is a rare glimmer and he returns to her house that evening. It is more likely that he is simply averse to being "read" in the way that he has "read" his quarry - similar, perhaps, to Florestine's aversion to being photographed in Ouida's story. It is a matter of privacy rather than propriety, and a moment of unself-conscious hypocrisy.

It is ironic, in a way, that photographs should act so unlike conventional clues in these stories. As scholars like Armstrong (1999) and Green-Lewis (1996) have pointed out, photography allowed for a new kind of visual evidence through its accuracy and openness to the unintended, insignificant, and coincidental details of reality. Jan von Brevern (2018: 112) suggests that it was in part photography's inclusion of even the tiniest of details in the field of depiction that led to the sense that such details might be read in the manner of clues - as in, for instance, Sherlock Holmes' readings of cigarette stubs and other seemingly innocuous 
details. For von Brevern, photography introduced "a new class of details" through which one might read the world. As our scholarship has shown, Victorian novelists used a range of techniques related to visual media to portray this newly detailed world. For short picture stories about photographs, however, the primary interest is not in how to portray the world, but in how visual images might be read and misread, just as in the short Holmes stories the principle interest is in the reading of visual details as clues. For most of the picture stories of this period, however, there is as much doubt as there is faith in the ability of observers to accurately discern truth in images. Sceptical of photography's claims to art or even to truth, John Ruskin ([1866] 1905: 150) considered the "truth" captured in a photograph comparable to that of an echo which is "true to a conversation" even though it "omits the most important syllables and reduplicates the rest." Picture stories like the ones cited above do not dwell on the details of the image, but instead focus on the viewer response to the image. In this way, rather than asking readers to accept the image as "truth," they are more interested in the distance between the sound and the echo and the misunderstandings that result.

In her study of "magic portrait" stories, Bellonby seeks in part to contextualise the most famous example, Oscar Wilde's novella The Picture of Dorian Gray (1890), pointing out that part of Wilde's achievement was his radical revision of a "well established, highly conventional, and heteronormative genre" (2012: 229) in his gender swapping the established trope of a beautiful woman being sacrificed for the sake of a beautiful portrait. It does not, I think, diminish Wilde's achievements in Dorian Gray to observe, as I have done here, that the picture story - or magic portrait - genre had long been a site of resistance to, as well as affirmation of, hegemonic heteronormative (and sometimes misogynistic) conventions. Stories like Ouida's "How One Fire Lit Another; Or, The Mischief Done by My Photograph" (1860), the anonymous "The Photograph" (1859) and "The Unfinished Picture: A Reverie" (1845) playfully subverted the genre's conventions, and especially in Ouida's example, they provide counter narratives to the values often espoused in those conventions. Bellonby's work, along with Manion's, has paved the way in drawing attention to this genre and is right in arguing that a "literary critical resurrection" is due. It is also worth drawing attention to the value of the short story form in providing an expedient vehicle for fictional explorations that are able to deal primarily, almost exclusively, with hermeneutical or other pictorial matters away from the competing demands that a longer fictional apparatus would place on the narrative. These popular stories provide a rich addition to our history not only of British aestheticism but also of the reception of photography and its relation to literary culture.

\section{Bibliography}

"The Altered Picture." 1854. Sharpe's London Magazine of Entertainment and Instruction for General Reading (January): 380-382.

Armstrong, Nancy. 1999. Fiction in the Age of Photography: The Legacy of British Realism. Cambridge, Mass.: Harvard University Press.

Bear, Jordan. 2015. Disillusioned: Victorian Photography and the Discerning Subject. University Park, Penn.: Pennsylvania State University Press. DOI: https://doi.org/10.5325/j.ctv14gp47d.

Bellonby, Diana E. 2012. A Secret History of Aestheticism: Magic-Portrait Fiction, 1829-1929. [doctoral dissertation] Vanderbilt University. Available at: https://etd.library.vanderbilt.edu.

Bryson, Norman. 1983. Vision and Painting: The Logic of the Gaze. Basingstoke: Macmillan. 
Calé, Luisa, and Patrizia Di Bello, eds. 2010. Illustrations, Optics and Objects in Nineteenth-Century Literary and Visual Culture. Basingstoke: Palgrave Macmillan. DOI: https://doi.org/10.1057/9780230297395.

Clayton, Owen. 2015. Literature and Photography in Transition, 1850-1915. London: Palgrave Macmillan. DOI: https://doi.org/10.1057/9781137471505.

Colligan, Colette, and Margaret Linley, eds. 2011. Media, Technology, and Literature in the Nineteenth Century. Farnham: Ashgate. DOI: https://doi.org/10.4324/9781315594569.

Collins, Charles Allston. 1858. "Her Face." Household Words, 18 (28 August): 258-64. Available at: http://www.djo.org.uk/household-words/volume-xviii/page-258.html.

Collins, Wilkie. 1856. "My Black Mirror." Household Words. 14 (6 September): 169-75. Available at: http://www.djo.org.uk/household-words/volume-xiv/page-169.html.

Di Bello, Patrizia. 2007. Women's Albums and Photography in Victorian England: Ladies, Mothers and Flirts. Aldershot: Ashgate.

Elder, Abraham. 1843. "The Fatal Picture.” Bentley's Miscellany, 13 (January): 374-81.

"Every-Day Essays on Science." 1848. Sharpe's London Magazine of Entertainment and Instruction for General Reading, 7 (July): 243-6.

"Facts and Fallacies." 1847. Bentley's Miscellany, 21 (January): 586-95.

Green-Lewis, Jennifer. 1996. Framing the Victorians: Photography and the Culture of Realism. Ithaca: Cornell University Press. DOI: https://doi.org/10.7591/9781501736728.

Green-Lewis, Jennifer. 2017. Victorian Photography, Literature, and the Invention of Modern Memory: Already the Past. London: Bloomsbury. DOI: https://doi.org/10.4324/ 9781003104056.

Gunning, Tom. 2003. "Re-newing Old Technologies: Astonishment, Second Nature, and the Uncanny in Technology from the Previous Turn-Of-The-Century." In Rethinking Media Change: The Aesthetics of Transition, edited by David Thorburn and Henry Jenkins, 39-60. Cambridge, Mass.: MIT Press. DOI: https://doi.org/10.7551/mitpress/5930.003.0006.

Hoffman, Jesse. 2014. "Dante Gabriel Rossetti's Bad Photographs." Victorian Studies, 57.1: 57-87. DOI: https://doi.org/10.2979/victorianstudies.57.1.57.

Hooton, Charles. 1846. "The Story of the Unfinished Picture: A German Artist's Tale." New Monthly Magazine and Humorist, 78 (November): 348-53.

Kenney, Charles. 1845. “The Unfinished Picture: A Reverie.” Bentley's Miscellany, 18 (July): 411-24.

Leonardi, Nicoletta, and Natale, Simone. 2018. Photography and Other Media in the Nineteenth Century. University Park, Penn.: Penn State University Press. DOI: https://doi.org/10.5325/j.ctv14gp7mj.

"Life in a Drop of Water." 1856. Sharpe's London Magazine of Entertainment and Instruction for General Reading, 8 (January): 140-3.

"The Lost Picture." 1853. The London Journal and Weekly Record of Literature, Science, and Art, 18 (19 November): 186-9.

Manion, Deborah. 2010. The Ekphrastic Fantastic: Gazing at Magic Portraits in Victorian Fiction. [doctoral dissertation] University of Iowa. Available at: https://ir.uiowa.edu/cgi/ viewcontent.cgi? article $=5399 \&$ context $=$ etd .

Manion, Deborah. 2016. "Pregnant by a portrait: the dynamics of desire for Hardy's 'Imaginative Woman." In Thomas Hardy's Short Stories: New Perspectives, edited by Juliette Berning Schaefer and Siobhan Craft Brownson, 68-83. London: Routledge.

Medwin (Captain) [unknown first name]. 1843. "The Adventures of a Picture." Ainsworth's Magazine, 3 (February): 155-60.

"Memoirs of an Old Picture." 1859. The Leisure Hour: a Family Journal of Instruction and Recreation, 8 (10 February): 91-5.

Mitchell, W.J.T. 1994. Picture Theory. Chicago: University of Chicago Press. 
Moretti, Franco. 2000. "The Slaughterhouse of Literature." MLQ: Modern Language Quarterly, 61.1: 207-27. DOI: https://doi.org/10.1215/00267929-61-1-207.

"New Inventions." 1853. The London Journal and Weekly Record of Literature, Science, and Art, 18 (19 November): 189-90.

Novak, Daniel A. 2008. Realism, Photography and Nineteenth-Century Fiction. Cambridge: Cambridge University Press.

"On the Threatened Extinction of Ghosts". 1856. Sharpe's London Magazine of Entertainment and Instruction for General Reading, 8 (January): 175-8.

Ouida. 1860. "How One Fire Lit Another; Or, The Mischief Done by My Photograph". Bentley's Miscellany, 47 (January, February): 423-40; 531-42.

"The Photograph." 1859. Sharpe's London Magazine of Entertainment and Instruction for General Reading, 30 (July) 229-32.

“The Photograph.” 1859. Ladies' Cabinet of Fashion, n.v. (September): n.p.

Potter, Jonathan. 2018. Discourses of Vision in Nineteenth-Century Britain: Seeing, Thinking, Writing. London: Palgrave Macmillan. DOI: https://doi.org/10.1007/978-3-319-89737-0.

Ruskin, John. [1866] 1905. The Cestus of Aglaia and The Queen of the Air, with Other Papers and Lectures on Art and Literature 1860-1870 (vol. 19). In The Complete Works of John Ruskin, edited by E.T. Cook \& A. Wedderburn. 39 vols. Available at: https://www.lancaster.ac.uk/theruskin/the-complete-works-of-ruskin .

"Science, \&c." 1853. The London Journal and Weekly Record of Literature, Science, and Art, 18 (19 November): 189.

"The Story of a Picture." 1842. Chamber's Edinburgh Journal, 11 (5 February): 17-18.

"The Telescope." 1846. Sharpe's London Magazine of Entertainment and Instruction for General Reading, 2 (September): 310-12.

Teukolsky, Rachel. 2015. "Cartomania: Sensation, Celebrity, and the Democratized Portrait." Victorian Studies, 57.3: 462-75. DOI: https://doi.org/10.2979/victorianstudies.57.3.462

"The Unowned Picture." 1856. Sharpe's London Magazine of Entertainment and Instruction for General Reading, 8 (January): 353-4.

"The Veiled Picture." 1833. The New Monthly Magazine and Literary Journal, 1 (April): 467-74.

"The Veiled Picture: A Tale of the Fine Arts." 1858. The London Journal and Weekly Record of Literature, Science, and Art, 27 (27 March) 58-60.

von Brevern, Jan. 2018. "Two or Three Things Photography Did to Painting." in Photography and Other Media in the Nineteenth Century. edited by Nicoletta Leonardi and Simone Natale. University Park, Penn.: Pennsylvania State University Press, 103-15. DOI: https://doi.org/10.5325/j.ctv14gp7mj.12.

Walter, Leslie. 1863. "In a Stereoscope." The London Reader of Literature, Science, Art and General Information, 1 (10 October) 685-87.

Walter, Leslie. 1864. "In a Stereoscope." Sharpe's London Magazine of Entertainment and Instruction for General Reading, 25 (August): 83-9. 